\title{
Novel peptide-dendrimer conjugates as drug carriers for targeting nonsmall cell lung cancer
}

This article was published in the following Dove Press journal:

International Journal of Nanomedicine

21 December 2010

Number of times this article has been viewed

\section{Jianfeng Liu' ${ }^{1,2}$ \\ Jinjian Liu $^{2}$ \\ Liping $\mathrm{Chu}^{2}$ \\ Yanming Wang ${ }^{3}$ \\ Yajun Duan' \\ Lina Feng ${ }^{2}$ \\ Cuihong Yang' \\ Ling Wang ${ }^{3}$ \\ Deling Kong'}

'The Key Laboratory of Bioactive Materials, Ministry of Education, College of Life Science, Nankai University, Tianjian, People's Republic of China; ${ }^{2}$ Tianjin Key Laboratory of Molecular Nuclear Medicine, Institute of Radiation Medicine, Chinese Academy of Medical Science and Peking Union Medical College,

Tianjian, People's Republic of China; ${ }^{3}$ College of Pharmacy, Nankai University, Tianjin, People's Republic of China
Correspondence: Deling Kong Institute of Molecular Biology, Nankai University, Tianjin 30007I, People's Republic of China

Tel +8622235021 I I

Fax +862223498775

Email kongdeling@nankai.edu.cn Jianfeng Liu

Institute of Radiation Medicine, Tianjin 300192 , People's Republic of China

Tel +862285683019

Email lewis78@I63.com
Abstract: Phage display technology has been demonstrated to be a powerful tool for screening useful ligands that are capable of specifically binding to biomarkers on the surface of tumor cells. The ligands found by this technique, such as peptides, have been successfully applied in the fields of early cancer diagnostics and chemotherapy. In this study, a novel nonsmall cell lung cancer-targeting peptide (LCTP, sequence RCPLSHSLICY) was screened in vivo using a Ph.D.-C7C ${ }^{\mathrm{TM}}$ phage display library. In order to develop a universal tumor-targeting drug carrier, the LCTP and fluorescence-labeled molecule (FITC) were conjugated to an acetylated polyamidoamine (PAMAM) dendrimer of generation 4 (G4) to form a PAMAM-Ac-FITCLCTP conjugate. The performance of the conjugate was first tested in vitro. In vitro results of cell experiments analyzed by flow cytometry and inverted fluorescence microscopy indicated that PAMAM-Ac-FITC-LCTP was enriched more in NCI-H460 cells than in 293T cells, and cellular uptake was both time- and dose-dependent. The tissue distribution of the conjugate in athymic mice with lung cancer xenografts was also investigated to test the targeting efficiency of PAMAM-Ac-FITC-LCTP in vivo. The results showed that LCTP can effectively facilitate the targeting of PAMAM-Ac-FITC-LCTP to nonsmall cell lung cancer cells and tumors. These results suggest that the LCTP-conjugated PAMAM dendrimer might be a promising drug carrier for targeted cancer diagnosis and treatment.

Keywords: polyamidoamine dendrimer, in vivo phage display, targeted drug delivery, peptide, nonsmall cell lung cancer

\section{Introduction}

Nonspecific anticancer chemotherapy has no tumor targeting effect and will kill normal and cancer cells, causing severe side effects in many patients. To solve this problem, targeted drug delivery systems have received great attention. ${ }^{1}$ In this system, drugs can be specifically targeted to the tumors, increase drug solubility, ${ }^{2,3}$ prolong time of drugs in the circulation, protect drugs from degradation, and improve their metabolic kinetics. ${ }^{4,5}$ To date, liposomes, ${ }^{6}$ micelles, ${ }^{7,8}$ and dendrimers ${ }^{9}$ conjugated with specific ligands have been identified as being able to target drugs to cancer cells.

Polyamidoamine (PAMAM) dendrimers have attracted considerable research interest as drug carriers due to their unique properties, ie, hyperbranched and monodispersed tree-like structures with multifunctional surfaces, enabling the dendrimers to encapsulate or conjugate drug molecules. Moreover, the terminal groups of PAMAM can be easily modified (by, eg, acetylation or poly(ethyleneglycol) modification [PEGylation]) to improve their solubility and biocompatibility. In order to improve the targeting capability of PAMAM, many targeting molecules, such as antibodies, ${ }^{10}$ folic acid, ${ }^{11,12}$ biotin, ${ }^{13}$ 
peptides, ${ }^{14-17}$ and carbohydrates ${ }^{18,19}$ have been connected to PAMAM dendrimers. Finally, chemotherapy drugs have been covalently bound to these dendrimers ${ }^{20,21}$ or encapsulated in the internal cavities of dendritic molecules ${ }^{11,22}$ to generate targeted drug delivery systems.

A key factor of a targeted drug delivery system is the finding of targeting molecules that can specifically recognize tumor and cancer cells. Phage display technology is a powerful approach to screening targeting molecules, such as peptides, for cancer cells or tumor blood vessel endothelial cells. ${ }^{23,24}$ Many novel angiogenic vessels and homing peptides have been isolated recently using this method. ${ }^{17,25,26}$ Furthermore, in vivo phage display can screen cancer-binding peptides regardless of whether the receptor is known or not. Therefore, this technique can quickly screen cancer-specific peptides. ${ }^{27,28}$ In addition to drug delivery systems, tumor-targeting peptides are also employed in diagnosis or radiotherapy by delivering radionuclide. ${ }^{29-31}$ Some peptides discovered by phage display are even able to inhibit cancer growth and induce cancer cell apoptosis. $^{32,33}$

In order to develop a universal drug carrier for nonsmall cell lung cancer chemotherapy, a Ph.D.-C7C ${ }^{\mathrm{TM}}$ (New England Biolabs, Beverly, MA) phage display library was utilized to screen peptides specific for nonsmall cell lung cancer. It has become generally accepted that organs have their own special markers. Such heterogeneity was reported after it became apparent that endothelial cells in different organs display organ-specific markers. The phage display library includes all possible peptide sequences, and some random peptides displayed by phage can bind specifically with tumor-specific markers displayed by nonsmall cell lung cancer, based on protein-protein interactions. The phage displaying specific peptides would home to the tumor site, after intravenous injection. The tumor is then harvested and the phage therein collected and amplified. After four to five rounds, the phage including the tumor-specific targeting peptide can be isolated and the inserted peptide sequence translated by the phage DNA sequence. In our study, a novel peptide, lung cancertargeting peptide (LCTP; RCPLSHSLICY), was discovered which can specifically target nonsmall cell lung cancer. The LCTP was then conjugated with fluoresceinisothiocyanate (FITC, a fluorescence labeling agent used as a tracer) and acetylated PAMAM to generate a targeted drug delivery carrier (PAMAM-Ac-FITC-LCTP). The performance of this drug carrier was evaluated by in vitro culturing NCIH460 and 293T cells and in vivo using athymic mice with lung cancer xenografts. Our results showed that the modified PAMAM peptide dendrimer could be easily taken up by NCI-H460 cells in vitro and by tumors in vivo.

\section{Materials and methods Materials}

Phenyl methyl sulphonyl fiuoride (PMSF), isopropyl $\beta$-D-1thiogalactopyranoside (IPTG), aprotinin, leupeptin, 5-bromo4-chloro-3- indolyl- $\beta$-D-galactopyranoside (X-gal), FITC, 5,5-dithiobis-2-nitrobenzoic acid (DTNB), and polyamidoamine (G 4) were purchased from Sigma-Aldrich (St Louis, MO). Dialysis membrane (MWCO, 3500) was purchased from BBI Inc (Shanghai, China). 3-(4,5-dimethylthiazol-2yl)-2,5-diphenyl tetrazolium bromide (MTT), all cell culture media, and supplies were purchased from Gibco Corporation (Grand Island, NE).

The NCI-H460 cell line was kindly provided by Dr Yong Wang (Institute of Radiation Medicine, Chinese Academy of Medical Sciences, Tianjin, China). The 293T cell line was purchased from Keygen Co (Nanjing, China). Phage DNA sequencing was performed by Shanghai Sangon Corp (Shanghai, China). Peptides were synthesized by GL Biochem Ltd (Shanghai, China). BALB/c-nu/nu athymic mice (female, 4-6 weeks old) were purchased from the Laboratory Animal Center of The Academy of Military Medical Sciences (Beijing, China). The animal studies were performed in accordance with the Regulations for the Administration of Affairs Concerning Experimental Animals (Tianjin, revised in June 2004) and adhered to the Guiding Principles in the Care and Use of Animals of the American Physiological Society. The Ph.D.$\mathrm{C}^{7 \mathrm{TM}}$ phage display peptide library kit was used to screen specific peptides binding to human lung cancer xenografts on BALB/c-nu/nu athymic mice.

The phage display library kit is based on a combinatorial library of random peptide 7-mers fused to the $\mathrm{N}$ terminus of the minor coat protein (cpIII) of M13 phage. The random sequence is flanked by a pair of cysteine residues. Under nonreducing conditions, the cysteines spontaneously form a disulfide crosslink, resulting in phage display of cyclized peptides. The titer of the library is $2 \times 10^{13}$ plaque-forming units (pfu). The library consists of $1.2 \times 10^{9}$ electroporated sequences (compared with $20^{7}=1.28 \times 10^{9}$ possible sevenresidue sequences). Extensively sequencing the naive library has revealed a wide diversity of sequences with no obvious positional biases. The Escherichia coli host strain ER2738 (Arobust F+ strain with a rapid growth rate; New England Biolabs) was used for M13 phage propagation.

\section{In vivo phage display screening and peptide synthesis}

BALB/c-nu/nu athymic mice (female, 4-6 weeks) were used, and $2 \times 10^{7} \mathrm{NCI}-\mathrm{H} 460$ cells in $0.2 \mathrm{~mL}$ of Roswell Park Memorial Institute 1640 (RPMI-1640) medium were 
subcutaneously injected in the right flank to produce lung cancer xenografts. A Ph.D.-C7C phage display peptide library, which contained $2 \times 10^{11} \mathrm{pfu}$ was mixed with $200 \mu \mathrm{L}$ of Dulbecco's modified Eagle's medium (DMEM), and injected into the mice through the tail vein when the tumor grew up to about $0.5 \mathrm{~cm}$ in diameter. After circulation for 5 minutes, the mice were sacrificed, and perfused by injection of $50 \mathrm{~mL}$ phosphate-buffered saline through the heart to wash the unbounded phage. Then the tumors were harvested, weighed, and ground in $1 \mathrm{~mL}$ of DMEM-PI (DMEM containing the protease inhibitors PMSF [1 mM], aprotinin $[20 \mu \mathrm{g} / \mathrm{mL}]$, and leupeptin $[1 \mu \mathrm{g} / \mathrm{mL}])$. The tissue was washed five times with ice-cold DMEM-PI containing $1 \%$ bovine serum albumin. After centrifugation, the phage particles were amplified by ER2738 bacteria overnight at $37^{\circ} \mathrm{C}$. The phages were titered on agar plates in the presence of IPTG/X-gel $(1 \mathrm{mg} / \mathrm{L})$ and tetracycline (40 $\mu \mathrm{g} / \mathrm{mL}$ ). The amplified phage was injected into the mice to repeat the above procedures. This screening was repeated for five rounds. ${ }^{17,27,34}$ At the end of the fifth round, the phage was eluted and titered on LB/ IPTG/X-gel plates. The phage clones were randomly selected, and the inserted DNA sequence was determined using primer 5'-CCCTCATAGTTAGCGTAACG-3' (New England Biolabs). The phage-displayed peptides were translated and synthesized according the DNA sequences.

\section{Synthesis of acetylated PAMAM dendrimer}

The acetylated PAMAM dendrimer (PAMAM-Ac) was synthesized according to the method described in the literature. ${ }^{13,16,35}$ Briefly, $1.012 \mathrm{~g}$ (MW 14215, $\left.71.2 \mu \mathrm{mol}\right)$ of PAMAM dendrimer in $120 \mathrm{~mL}$ anhydrous methanol $(\mathrm{MeOH})$ was reacted with $0.214 \mathrm{~g}(2.110 \mathrm{mmol})$ of acetic anhydride overnight at room temperature with stirring in the presence of $0.352 \mathrm{~g}(3.454 \mathrm{mmol})$ of triethylamine. After evaporation, the product was dialyzed for 3 days against phosphate-buffered saline and double-distilled water using the dialysis membrane $(\mathrm{MWCO}=3500 \mathrm{Da})$, then lyophilized, and $1.165 \mathrm{~g}$ of PAMAM-Ac was obtained. The average number of acetyl groups grafted to each PAMAM molecule was determined by ${ }^{1} \mathrm{H}$ nuclear magnetic resonance calibration.

\section{Conjugation of FITC to acetylated PAMAM dendrimer}

FITC (38.2 mg, $98.1 \mu \mathrm{mol})$ was added dropwise into $40 \mathrm{~mL}$ of dimethyl sulfoxide (DMSO) solution containing $0.401 \mathrm{~g}$ (MW $15433,25.9 \mu \mathrm{mol})$ of PAMAM-Ac. The reaction mixture was allowed to stir overnight. The product was dialyzed against phosphate-buffered saline and double-distilled water using dialysis membrane $(\mathrm{MWCO}=3500 \mathrm{Da})$ for 3 days in a dark room, and the adsorbance at $500 \mathrm{~nm}$ of the eluent was detected to ensure that all free FITC was removed. The product was then lyophilized in a dark room, and $0.387 \mathrm{~g}$ of PAMAM-Ac-FITC was obtained. The average number of FITC molecules conjugated to each PAMAM molecule was determined by ${ }^{1} \mathrm{H}$ nuclear magnetic resonance calibration and ultraviolet-visible adsorbance (Varian Cary 100 bio ultraviolet-visible spectrophotometer).

\section{Conjugation of peptides to FITC-labeled dendrimer}

The solution containing $9.1 \mathrm{mg}(90.9 \mu \mathrm{mol})$ of succinic anhydride in $6 \mathrm{~mL}$ of anhydrous $\mathrm{MeOH}$ was added dropwise into a solution of $0.103 \mathrm{~g}$ (MW 16601, 6.2 $\mu \mathrm{mol}$ ) of PAMAM-Ac-FITC and $24.5 \mathrm{mg}$ of $(0.242 \mathrm{mmol})$ triethanolamine (TEA) in $90 \mathrm{~mL}$ of anhydrous $\mathrm{MeOH}$ with stirring. After overnight reaction at room temperature, the solvent was evaporated, and then the crude product was dialyzed $(\mathrm{MWCO}=3500 \mathrm{Da})$ and lyophilized using the aforementioned method; $12.8 \mathrm{mg}$ (MW 18001, $0.71 \mu \mathrm{mol}$ ) of the above product was then reacted with $2.0 \mathrm{mg}(10.4 \mu \mathrm{mol})$ of 1-[3-(dimethylamino)-propyl]-3-ethyl-carbodimide $\mathrm{HCl}$ (EDC) in $4 \mathrm{~mL}$ of water for 3 hours. Then $9.2 \mathrm{mg}(7.1 \mu \mathrm{mol})$ of the LCTP in $1 \mathrm{~mL}$ of DMSO was added dropwise to the above solution and stirred overnight. The crude product was dialyzed (MWCO $=3500 \mathrm{Da}$ ) using the aforementioned method, and the adsorbance at $275 \mathrm{~nm}$ of the elute was detected to ensure that all free peptide was removed. Then the product was lyophilized in a dark room. The average number of peptides conjugated to the dendrimer was determined using the Ellman assay. ${ }^{36} \mathrm{~A}$ standard curve was plotted with free LCTP. During the process, an excess of sodium sulfite was added to the peptide solution at $\mathrm{pH} 9.0$ to cleave the disulfide bond, and the reaction was carried out in a dark room. The adsorbance at $412 \mathrm{~nm}$ was used to calculate the number of peptides conjugated to the dendrimer according to the standard curve.

\section{Laser light-scattering assay}

Samples of PAMAM-Ac, PAMAM-Ac-FITC, and PAMAMAc-FITC-LCTP were filtered (pore size, $0.45 \mathrm{~mm}$ ) and analyzed with a light-scattering spectrometer (BI-200SM; Brookhaven Instruments, Holtsville, NY), equipped with a digital correlator (BI-9000AT; Brookhaven Instruments) to determine the granulometric distribution of the conjugates at $532 \mathrm{~nm}$. 


\section{Cell culture}

NCI-H460 cells were cultured in RPMI-1640 medium and 293 T cells in DMEM medium. The medium was supplemented with $10 \%$ fetal bovine serum, $1 \%$ penicillin, and $100 \mu \mathrm{g} / \mathrm{mL}$ streptomycin. Cells were grown at $37^{\circ} \mathrm{C}$ in $5 \% \mathrm{CO}_{2}$.

\section{Cytotoxicity assay}

The cytotoxicity of the PAMAM, PAMAM-Ac, PAMAMAc-FITC, and PAMAM-Ac-FITC-LCTP were evaluated by the MTT assay. The $293 \mathrm{~T}$ cells were seeded into 96-well plates at a density of $10^{4}$ cells/well and incubated for 24 hours. The filtrate of the samples $(0.22 \mu \mathrm{m})$ was added to the cells at different concentrations $(0,0.125,0.25,0.5,1.0,2.0$, and $4.0 \mu \mathrm{M})$. After incubation for another 24 hours, $25 \mu \mathrm{L}$ of MTT solution ( $5 \mathrm{mg} / \mathrm{mL}$ in phosphate-buffered saline) was added to each well. Four hours later, the medium containing MTT was removed, and the samples in the wells were air dried. Acidic isopropanol $(100 \mu \mathrm{L}, 0.04 \mathrm{M} \mathrm{HCl}$ in absolute isopropanol) was added to dissolve the formazen crystals. The optical density of the solution was measured at $570 \mathrm{~nm}$ using a microplate reader (Labsystem; Multiskan, Ascent, Finland).

\section{In vitro cellular uptake assay}

$293 \mathrm{~T}$ and NCI-H460 cells were seeded in 24-well plates at a density of $10^{4}$ cells/well. After 24 hours, the cells were incubated with PAMAM-Ac-FITC or PAMAM-Ac-FITCLCTP at different concentrations ranging from 0.05 to $1.0 \mu \mathrm{M}$ for 4 hours, or incubated with $0.25 \mu \mathrm{M}$ of PAMAMAc-FITC-LCTP at different intervals ranging from 0.5 to 8.0 hours. To compare the uptake efficiency between $293 \mathrm{~T}$ cells and NCI-H460 cells, the two cell lines were incubated with $0.5 \mu \mathrm{M}$ of the conjugates for 4 hours. To examine the competitive uptake, 293T cells and NCI-H460 cells were preincubated with $20 \mu \mathrm{M}$ free LCTP for 1 hour before the conjugates were added. At the end of incubation, the cells were trypsinized, washed with physiologic saline three times, and we then proceeded to fluorescence-activated cell sorting (FACS) analysis (Altra FCM; Beckman Coulter, Miami, FL). The uptake efficiency was expressed as the percentage of FITC-positive cells. The cells were also viewed under a confocal microscope (DMI6000B; Leica, Wetzlar, Germany) and an inverted fluorescence microscope. Images were recorded using CCD (ECLIPSE TE2000-U; Nikon, Tokyo, Japan).

\section{In vivo targeting assay}

$\mathrm{BALB} / \mathrm{c}-\mathrm{nu} / \mathrm{nu}$ athymic mice with lung cancer xenografts were prepared as described earlier. Mice were used for experiment when the diameter of tumor xenografts reached $0.4-0.6 \mathrm{~cm}$.
The animals were randomly divided into two groups. A $0.3 \mathrm{~mL}$ solution of PAMAM-Ac-FITC or PAMAM-Ac-FITC-LCTP (10 $\mu \mathrm{M}$ in phosphate-buffered saline) was injected through the tail vein of the animal. Four hours later, the tumors and main organs (heart, liver, lung, spleen, kidney, thyroid, brain, and ovary) were harvested and proceeded to imaging (KODAK IS in vivo FX; Kodak, New Haven, CT). The relative fluorescence intensity per unit area was calculated using KODAK 5.1 software (KODAK IS in vivo FX).

\section{Statistical analysis}

The unpaired Student's $t$-test was used to evaluate the significance between experimental groups. A value of $P<0.05$ was considered to be statistically significant.

\section{Results}

\section{Screening and peptide synthesis}

After five rounds of screening, 40 random phage clones were amplified and the DNA sequences were determined. The phage displayed peptide sequences were translated (see Table 1). The most frequent peptide sequence was ACPLSHSLIC, and the binding sequence with nonsmall cell lung cancer was the sequence between the two cysteine residues. In order to connect the peptide to the PAMAM dendrimer, the alanine residue was replaced by arginine. For ${ }^{125}$ I-labeling, a tyrosine residue was added to the end of the peptide. The final peptide sequence synthesized was RCPLSHSLICY, which was cyclized with two cysteine residues, marked LCTP (see supporting information for the HPLC and MS spectra of the synthesized peptide).

\section{Preparation of PAMAM-Ac-FITC-LCTP conjugate}

The synthetic route of PAMAM-Ac-FITC-LCTP conjugate is shown in Figure 1. The degree of PAMAM-Ac

Table I The displayed peptide sequences of screening phage from in vivo lung cancer xenografts

\begin{tabular}{lll}
\hline Phage clone & Peptide sequence & Frequency \\
\hline A-2 & ACPLSHSLIC & $28 / 37$ \\
A-7 & ACSVAPDNLC & $3 / 37$ \\
B-II & ACAQSYHVWC & $2 / 37$ \\
A-6 & ACWFSNIAKC & $1 / 37$ \\
A-13 & ACSHFVYGIC & $1 / 37$ \\
B-3 & ACVNGRMTDC & $1 / 37$ \\
B-7 & ACPLKANLSC & $1 / 37$ \\
\hline
\end{tabular}

Notes: Forty phage clones were random selected from two plates $(A$ and $B)$ and 37 phage displayed peptide sequences were identified. The first, second, and tenth residues are alanine, cysteine, and cysteine, respectively. The inner random seven peptides were cyclized by the two cysteine residues. 

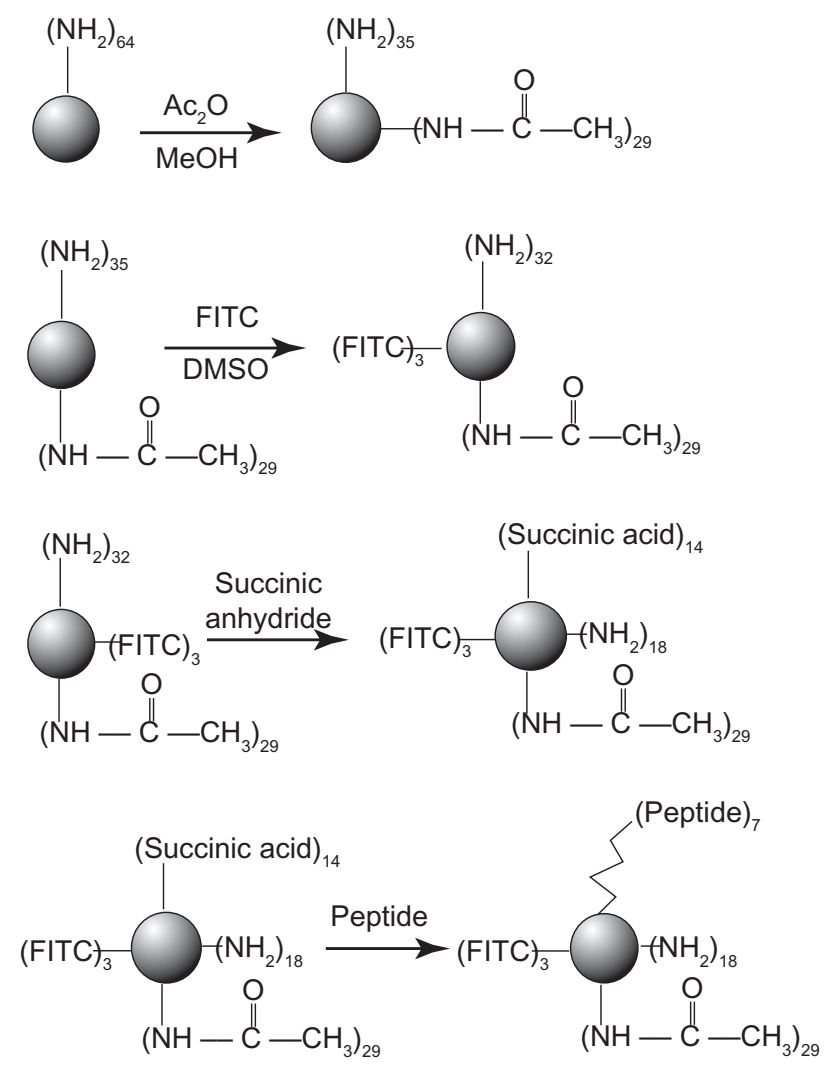

Figure I Synthetic scheme of polyamidoamine dendrimer generation 4 fluorescencelabeled acetylated polyamidoamine lung cancer targeting peptide.

acetylation was measured by ${ }^{1} \mathrm{H}$ nuclear magnetic resonance $\left(300 \mathrm{mHz}, \mathrm{D}_{2} \mathrm{O}\right)$; the aliphatic peaks appear at $1.80 \mathrm{ppm}$, $2.24 \mathrm{ppm}, 2.46 \mathrm{ppm}, 2.64 \mathrm{ppm}, 2.93 \mathrm{ppm}, 3.12 \mathrm{ppm}$, $3.23 \mathrm{ppm}$, and $3.30 \mathrm{ppm}$. The integration ratio of methylene protons signal of $-\mathrm{CH}_{2} \mathrm{C}(\mathrm{O})-$ at $\delta 2.24 \mathrm{ppm}(248 \mathrm{H})$ and methyl protons signal of $-\mathrm{C}(\mathrm{O}) \mathrm{CH}_{3}$ at $\delta 1.80$ ppm was 2.84 , indicating that about 29 acetyl groups were grafted to each PAMAM molecule (PAMAM- $\mathrm{Ac}_{29}$ ). Conjugation of FITC to PAMAM-Ac was characterized by ${ }^{1} \mathrm{H}$ nuclear magnetic resonance $\left(300 \mathrm{mHz}, \mathrm{D}_{2} \mathrm{O}\right)$ and ultraviolet-visible spectrum. The aliphatic peaks appear at $1.80 \mathrm{ppm}$, $2.23 \mathrm{ppm}, 2.44 \mathrm{ppm}, 2.63 \mathrm{ppm}, 2.94 \mathrm{ppm}, 3.11 \mathrm{ppm}$, $3.29 \mathrm{ppm}$, and $3.30 \mathrm{ppm}$. The aromatic peaks at $6.37 \mathrm{ppm}$, $6.96 \mathrm{ppm}, 7.42 \mathrm{ppm}$, and $7.67 \mathrm{ppm}$ corresponded to the protons in FITC. FITC has a characteristic absorbance peak at around $500 \mathrm{~nm}$ and not for PAMAM-Ac and the peptide (Figure 2). The number of FITC conjugated to PAMAM-Ac was about 3-4, which was determined based on the standard calibration curve of free FITC. The number of LCTP grafted to PAMAM-Ac-FITC was $7-8$ by Ellman assay (see supporting information for the ${ }^{1} \mathrm{H}$ nuclear magnetic resonance spectra of PAMAM-Ac, PAMAM-Ac-FITC, and PAMAM-Ac-FITC-LCTP).

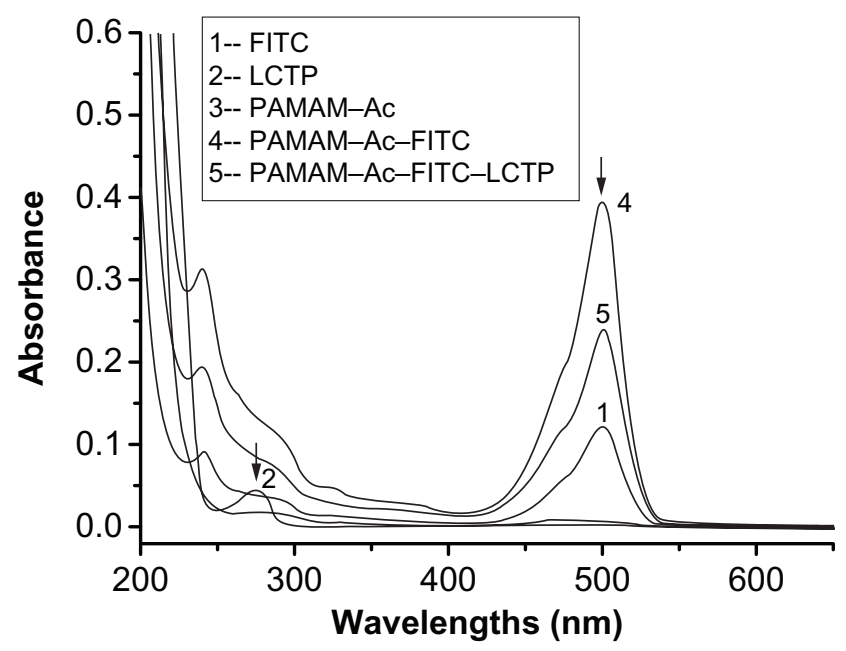

Figure 2 Ultraviolet-visible spectra of the synthesized polyamidoamine conjugates. The peak at $500 \mathrm{~nm}$ indicates the presence of fluorescence-labeling in the conjugates. The peptide adsorbance peak at $275 \mathrm{~nm}$ was overlapped with the broad adsorbance peak of fluorescence-labeling at $275 \mathrm{~nm}$.

\section{Cytotoxicity assay}

As shown in Figure 3, when the concentration of the polymers was higher than $2 \mu \mathrm{M}$, the cytotoxicity of PAMAM-Ac, PAMAM-Ac-FITC, and PAMAM-Ac-FITC-LCTP was lower than that of unmodified PAMAM. The cells viability was over $88 \%$, which suggests that the PAMAM-Ac-FITCLCTP conjugate has good biocompatibility.

\section{In vitro cellular uptake assay}

Figure 4A shows the uptake efficiencies of the two conjugates for 293T cells over 4 hours. The uptake efficiencies of both conjugates were nearly of equal value and were

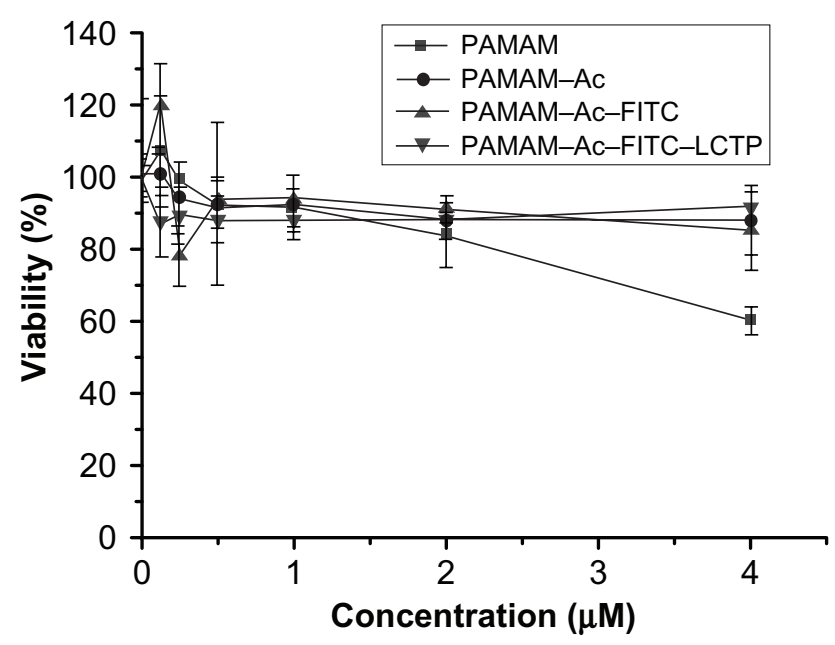

Figure 3 MTT assay for cellular toxicity of 293T cells. Cells were incubated with polyamidoamine, fluorescence-labeled acetylated polyamidoamine, acetylated polyamidoamine and fluorescence-labeled acetylated polyamidoamine lung cancer targeting peptide, at varied concentrations. The viability of the nontreated cells was arbitrarily defined as 100\%. Data are expressed as mean \pm standard deviation $(n=6)$. 

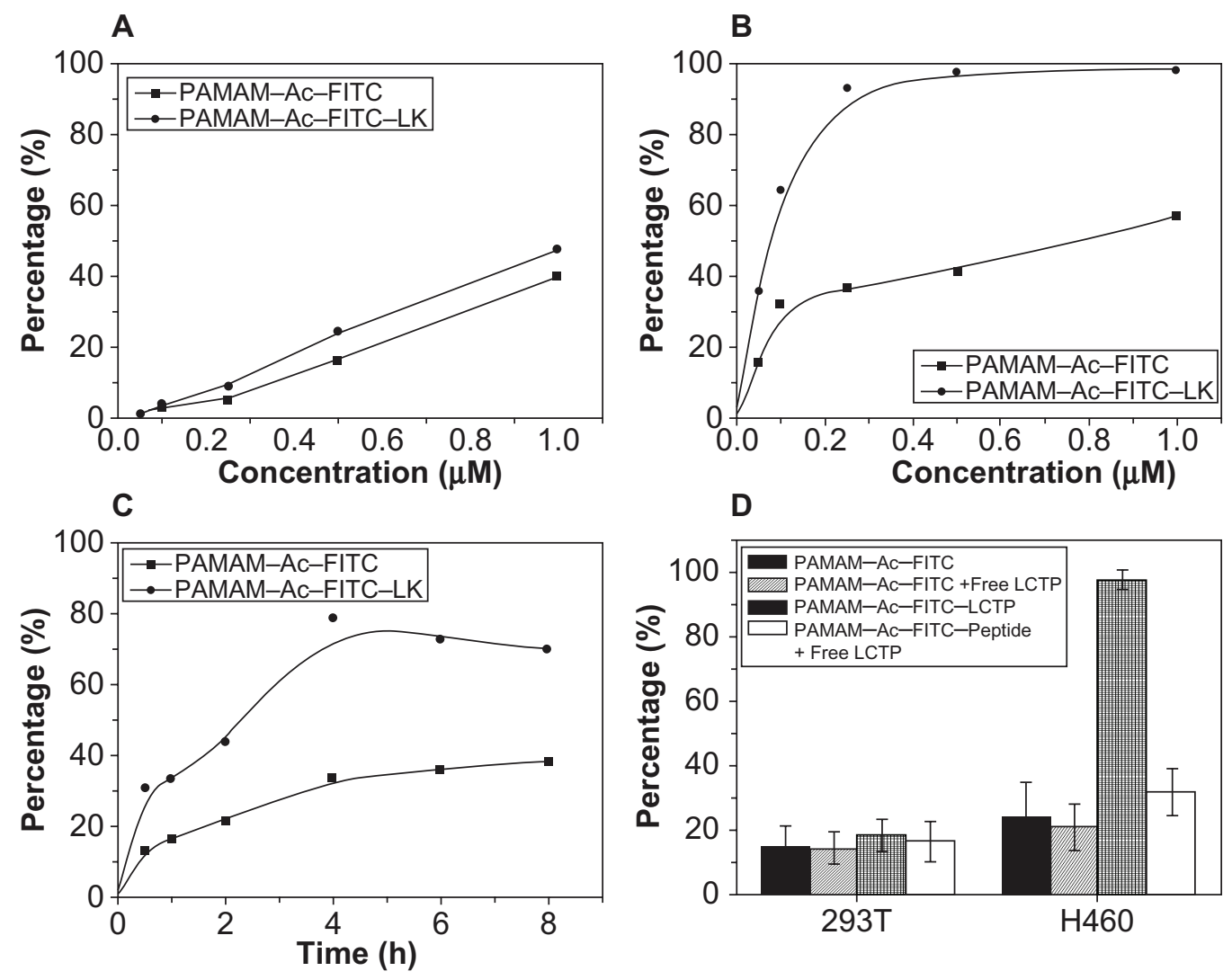

Figure 4 In vitro evaluation of dose-dependent uptake of the conjugates (fluorescence-labeled acetylated polyamidoamine and fluorescence-labeled acetylated polyamidoamine lung cancer targeting peptide) by $293 \mathrm{~T}$ cells $(\mathbf{A})$ and $\mathrm{NCl}-\mathrm{H} 460$ cells $(\mathbf{B})$ determined by fluorescence-activated cell sorting. The cells were incubated with various concentrations of the conjugates for 4 hours at $37^{\circ} \mathrm{C}$. C) Time-dependent uptake of the conjugates by $\mathrm{NCl}-\mathrm{H} 460$ cells. The $\mathrm{NCl}-\mathrm{H} 460$ cells were incubated with the conjugates at a concentration of $0.25 \mu \mathrm{M}$ for different time. D) Uptake of the conjugates by $293 \mathrm{~T}$ and $\mathrm{NCl}-\mathrm{H} 460$ cells. The incubation conditions were $0.5 \mu \mathrm{M}$ and four hours.

concentration-dependent. However, although the uptake efficiencies of the two conjugates by NCI-H460 cells were also concentration-dependent, but the uptake efficiency of the PAMAM-Ac-FITC-LCTP was much higher than that of PAMAM-Ac-FITC (Figure 4B). The cellular uptake of the conjugates by both cell lines was time-dependent, but reached saturation after incubation for 4 hours (Figure 4C). Under the same conditions, the uptake of PAMAM-AcFITC-LCTP by NCI-H460 cells was threefold higher than that of PAMAM-Ac-FITC, and more than threefold higher than the uptake of the two conjugates by $293 \mathrm{~T}$ cells. When preincubated with free LCTP, uptake of PAMAM-Ac-FITCLCTP by NCI-H460 cells was effectively decreased, but for 293 T cells and PAMAM-Ac-FITC there was almost no change (Figure 4D).

The uptake of PAMAM-Ac-FITC and PAMAM-AcFITC-LCTP by the cells was directly visualized under the inverted fluorescence microscope. As shown in Figure 5, the fluorescence signal of the PAMAM-Ac-FITC-LCTPtreated NCI-H460 cells (Figure 5D) was much stronger than those from the two conjugates-treated 293T cells and the PAMAM-Ac-FITC-treated NCI-H460 cells. A clear image was observed under confocal microscopy. Figure 5E shows the image of PAMAM-Ac-FITC-LCTP-treated NCI-H460 cells.

\section{In vivo targeting assay}

The distribution of PAMAM-Ac-FITC and PAMAM-AcFITC-LCTP in different organs was evaluated by measuring the fluorescence intensity of each organ at 4 hours after intravenous injection. Figure 6 showed the fluorescence density of the main organs. The highest density of the two conjugates was found in the kidney next in the tumors, followed by the brain and the lung. There was no difference in the distribution of the two conjugates among all the other organs, except in the tumors where the distribution of PAMAM-Ac-FITCLCTP was significantly higher than that of PAMAM-AcFITC $(P<0.01)$.

\section{Discussion}

In vivo phage display has been proven to be a useful method in isolating organ- or tumor-specific binding probes. The random 


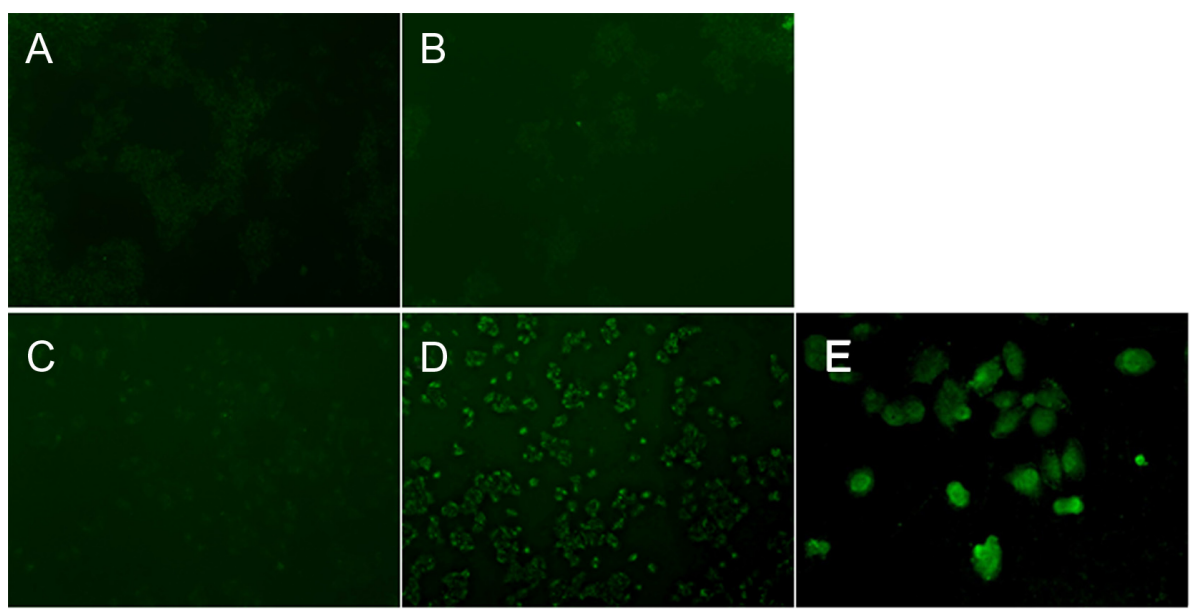

Figure $\mathbf{5}$ In vitro evaluation of the conjugates (fluorescence-labeled acetylated polyamidoamine and fluorescence-labeled acetylated polyamidoamine lung cancer targeting peptide) targeting to $293 \mathrm{~T}$ and $\mathrm{NCl}-\mathrm{H} 460$ cells determined by inverted fluorescence microscopy. The cells were incubated with the conjugates ( $0.5 \mu \mathrm{M}$ ) for 4 hours. $100 \times($ A) 293 T cells incubated with fluorescence-labeled acetylated polyamidoamine. B) 293T cells incubated with fluorescence-labeled acetylated polyamidoamine lung cancer targeting peptide. C) $\mathrm{NCl}-\mathrm{H} 460$ cells incubated with fluorescence-labeled acetylated polyamidoamine. D) $\mathrm{NCl}-\mathrm{H} 460$ cells incubated with fluorescence-labeled acetylated polyamidoamine lung cancer targeting peptide. E) local amplification of D.

sequence oligonucleotides were inserted into a specific site of phage DNA, then random sequence peptides or proteins were expressed and exposed on the phage surface. Because organs and tumors carry unique marker molecules, ${ }^{27,37}$ phage display can be used to screen organ- or tumor-specific peptide sequences for targeted drug delivery. The present study used an in vivo phage display method to screen peptides. Cyclic peptides have higher stability and binding capability, ${ }^{38}$ so the Ph.D.-C7C phage display peptide library kit was used, in which the inserted peptide were cyclized by two cysteine residues. As shown in the Table, the phage inserted ACPLSHSLIC sequence was amplified and enriched. Among the total of

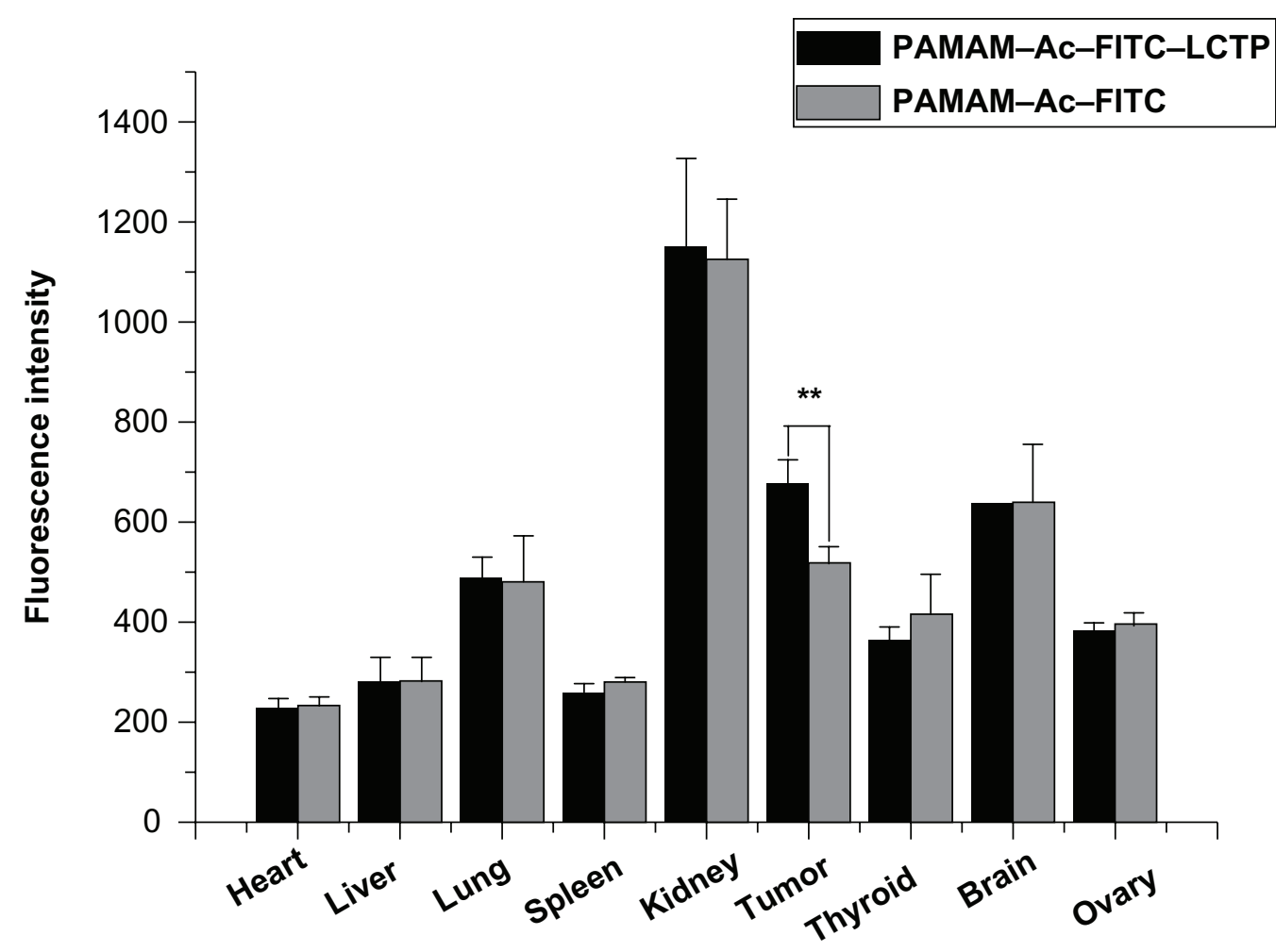

Figure 6 Distribution of fluorescence-labeled acetylated polyamidoamine and fluorescence-labeled acetylated polyamidoamine lung cancer targeting peptide 4 hours postinjection in athymic mice bearing nonsmall cell lung cancer tumor xenografts, the relative fluorescence intensity per unit area data are presented as mean \pm standard deviation ( $n=6, * * p<0.0$ Ifluorescence-labeled acetylated polyamidoamine lung cancer targeting peptide versus fluorescence-labeled acetylated polyamidoamine in tumor). 
37 phage displayed peptide sequences, 28 were the same, which was the ACPLSHSLIC peptide.

The cationic PAMAM has hemolytic toxicity. ${ }^{39}$ Several methods to decrease the hemolytic toxicity of PAMAM have been reported, one of which is the PEG modification. ${ }^{40-42}$ PEGylation can inhibit the nonspecific interactions between PAMAM and biomolecules and improve the biocompatibility of PAMAM, and can also decrease the immunogenicity and antigenicity of PAMAM. Another method is acetylation, which can decrease the positive charge density of PAMAM. In our studies, partially acetylated PAMAM displayed higher cell viability than PAMAM by the MTT assay. Further conjugation of FITC and the LCTP to the PAMAM-Ac had no influence on the biocompatibility of the dendrimer (Figure 3).

The uptake of PAMAM-Ac-FITC-LCTP by both 293 T and NCI-H460 cells was found to be time- and dosedependent. However, the uptake efficiency of PAMAMAc-FITC-LCTP by NCI-H460 cells was much higher than that of PAMAM-Ac-FITC. In contrast, the uptake of both conjugates by $293 \mathrm{~T}$ cells was very low. Similar results were previously reported by Hill et $\mathrm{al}^{16}$ and Shukla et al. ${ }^{43}$ In their studies, RGD peptide drove PAMAM conjugates specifically to MDPC-23 and HUVEC cancer cells, and enhanced cellular uptake. The free LCTP could greatly decrease NCI-H460 cell uptake of PAMAM-Ac-FITC-LCTP, but had no effect on NCI-H460 cell uptake of PAMAM-Ac-FITC and 293T cell uptake of PAMAM-Ac-FITC-LCTP and PAMAMAc-FITC. These observations suggest that LCTP played an important role in driving the conjugates highly and selectively to bind the membrane of NCI-H460 cells, thus facilitating the endocytosis process.

Because the penetration of FITC fluorescence through the body of mice is weak, in vivo imaging of live athymic mice bearing nonsmall cell lung cancer tumors cannot provide an exact fluorescence intensity. In this study, the tumors and organs were harvested and imaged ex vivo. The distribution ofPAMAM-Ac-FITC and PAMAM-Ac-FITC-LCTP conjugates in each organ was almost the same except that the tumors had significantly higher uptake of PAMAM-Ac-FITC-LCTP than PAMAM-Ac-FITC $(P<0.01)$. This result suggests that the targeting effect of LCTP might enhance the permeability of PAMAM-Ac-FITC-LCTP in nonsmall cell lung cancer tumor. Indeed, the difference of tumor uptake for the two conjugates was not remarkable, and more experiments need to be done to improve the targeting effect of the conjugate. The distribution of the conjugates among different organs was found in the following order: kidney $>$ tumor $\geq$ brain $>$ lung
$>$ thyroid $\geq$ ovary $>$ liver $\geq$ spleen $\geq$ heart (Figure 6 ). The highest distribution of the conjugates was found in the kidney 4 hours after injection which is probably due to the fact that kidney is the main organ that excretes waste out of the body. And four hours after the injection, part of the conjugates had moved to the metabolic system, which is a phenomenon often observed in drug pharmacokinetic studies. ${ }^{15,25}$ It was interesting that the distribution of the conjugate in the brain was similar to that in the tumors, indicating that this PAMAM conjugate can penetrate the blood-brain barrier and enter the brain. ${ }^{44,45}$

Although antibody, folic acid, and biotin are often used as targeting agents, the peptides screened here by an in vivo phage display method could target the unique receptors expressed by cancer cells, thus remarkably improved the targeting capability for chemotherapy.

\section{Conclusion}

In summary, NCI-H460 cell-specific LCTP was screened by the phage display method and conjugated to the acetylated PAMAM dendrimer. The specific LCTP-modified PAMAM dendrimer could be easily taken up by NCI-H460 cells in vitro and by tumors in vivo. These results indicate that the LCTP-dendrimer conjugate might be a useful drug carrier for cancer clinical diagnosis and treatment.

\section{Acknowledgments}

This study was financially support by the National Natural Science Foundation of China (30700178 and 20774050), the National Outstanding Youth Fund (30725030), Tianjin Natural Science Foundation (09JCYBJC13400), and the Development Foundation of the Institute of Radiation Medicine, Chinese Academy of Medical Sciences and Peking Union Medical College (SF0627, SF0823).

\section{Disclosure}

The authors report no conflicts of interest in this work.

\section{References}

1. Lammers T, Hennink WE, Storm G. Tumour-targeted nanomedicines: Principles and practice. Br J Cancer. 2008(3);99:392-397.

2. Prajapati RN, Tekade RK, Gupta U, Gajbhiye V, Jain NK. Dendimermediated solubilization: Formulation development and in vitro-in vivo assessment of piroxicam. Mol Pharm. 2009;6(3):940-950.

3. Svenson S, Chauhan AS. Dendrimers for enhanced drug solubilization. Nanomed. 2008;3(5):679-702.

4. Patil ML, Zhang M, Betigeri S, Taratula O, He H, Minko T. Surfacemodified and internally cationic polyamidoamine dendrimers for efficient siRNA delivery. Bioconjug Chem. 2008;19(7):1396-1403.

5. Kaminskas LM, Kelly BD, McLeod VM, et al. Pharmacokinetics and tumor disposition of PEGylated, methotrexate conjugated poly-1-lysine dendrimers. Mol Pharm. 2009;6(4):1190-1204. 
6. Panwar P, Pandey B, Lakhera PC, Singh KP. Preparation, characterization, and in vitro release study of albendazole-encapsulated nanosize liposomes. Int J Nanomedicine. 2010;5:101-108.

7. Gaucher G, Marchessault RH, Leroux JC. Polyester-based micelles and nanoparticles for the parenteral delivery of taxanes. J Control Release. 2010;143(1):2-12.

8. Matsumoto S, Christie RJ, Nishiyama N, et al. Environment-responsive block copolymer micelles with a disulfide cross-linked core for enhanced siRNA delivery. Biomacromolecules. 2009;10(1):119-127.

9. Samad A, Alam MI, Saxena K. Dendrimers: A class of polymers in the nanotechnology for the delivery of active pharmaceuticals. Curr Pharm Des. 2009;15(25):2958-2969.

10. Shukla R, Thomas TP, Peters JL, et al. HER2 specific tumor targeting with dendrimer conjugated anti-HER2 mAb. Bioconjug Chem 2006;17(5):1109-1115.

11. Singh P, Gupta U, Asthana A, Jain NK. Folate and folate-PEG-PAMAM dendrimers: Synthesis, characterization, and targeted anticancer drug delivery potential in tumor bearing mice. Bioconjug Chem. 2008;19(11) 2239-2252.

12. Swanson SD, Kukowska-Latallo JF, Patri AK, et al. Targeted gadoliniumloaded dendrimer nanoparticles for tumor-specific magnetic resonance contrast enhancement. Int J Nanomedicine. 2008;3(2):201-210.

13. Yang W, Cheng Y, Xu T, Wang X, Wen LP. Targeting cancer cells with biotin-dendrimer conjugates. Eur J Med Chem. 2009;44(2):862-868.

14. Yang H, Kao WJ. Synthesis and characterization of nanoscale dendritic RGD clusters for potential applications in tissue engineering and drug delivery. Int J Nanomedicine. 2007;2(1):89-99.

15. Boswell CA, Eck PK, Regino CA, et al. Synthesis, characterization, and biological evaluation of integrin alphavbeta3-targeted PAMAM dendrimers. Mol Pharm. 2008;5(4):527-539.

16. Hill E, Shukla R, Park SS, Baker JR Jr. Synthetic PAMAM-RGD conjugates target and bind to odontoblast-like MDPC 23 cells and the predentin in tooth organ cultures. Bioconjug Chem. 2007;18(6):1756-1762.

17. Lee TY, Lin CT, Kuo SY, Chang DK, Wu HC. Peptide-mediated targeting to tumor blood vessels of lung cancer for drug delivery. Cancer Res. 2007;67(22):10958-10965.

18. Chabre YM, Roy R. Recent trends in glycodendrimer syntheses and applications. Curr Top Med Chem. 2008;8(14):1237-1285.

19. Bhadra D, Yadav AK, Bhadra S, Jain NK. Glycodendrimeric nanoparticulate carriers of primaquine phosphate for liver targeting. Int J Pharm. 2005;295(1-2):221-233.

20. Wu G, Barth RF, Yang W, Kawabata S, Zhang L, Green-Church K. Targeted delivery of methotrexate to epidermal growth factor receptorpositive brain tumors by means of cetuximab (IMC-C225) dendrimer bioconjugates. Mol Cancer Ther. 2006;5(1):52-59.

21. Kurtoglu YE, Mishra MK, Kannan S, Kannan RM. Drug release characteristics of PAMAM dendrimer-drug conjugates with different linkers. Int J Pharm. 2010;384(1-2):189-194.

22. Bharali DJ, Khalil M, Gurbuz M, Simone TM, Mousa SA. Nanoparticles and cancer therapy: A concise review with emphasis on dendrimers. Int J Nanomedicine. 2009;4:1-7.

23. Smith GP. Filamentous fusion phage: Novel expression vectors that display cloned antigens on the virion surface. Science. 1985;228(4705): 1315-1317.

24. Scott JK, Smith GP. Searching for peptide ligands with an epitope library. Science. 1990;249(4967):386-390.

25. Hui X, Han Y, Liang S, et al. Specific targeting of the vasculature of gastric cancer by a new tumor-homing peptide CGNSNPKSC. J Control Release. 2008;131(2):86-93.

26. Yang W, Luo D, Wang S, et al. TMTP1, a novel tumor-homing peptide specifically targeting metastasis. Clin Cancer Res. 2008;14(17): 5494-5502.
27. Pasqualini R, Ruoslahti E. Organ targeting in vivo using phage display peptide libraries. Nature. 1996;380(6572):364-366.

28. Pasqualini R, Koivunen E, Ruoslahti E. Alpha v integrins as receptors for tumor targeting by circulating ligands. Nat Biotechnol. 1997;15(6): $542-546$.

29. Howell RC, Revskaya E, Pazo V, Nosanchuk JD, Casadevall A, Dadachova E. Phage display library derived peptides that bind to human tumor melanin as potential vehicles for targeted radionuclide therapy of metastatic melanoma. Bioconjug Chem. 2007;18(6):1739-1748.

30. Zitzmann S, Mier W, Schad A, et al. A new prostate carcinoma binding peptide (DUP-1) for tumor imaging and therapy. Clin Cancer Res. 2005;11(1):139-146.

31. Zitzmann S, Krämer S, Mier W, et al. Identification and evaluation of a new tumor cell-binding peptide, FROP-1. J Nucl Med. 2007;48(6): 965-972.

32. Chen B, Cao S, Zhang Y, et al. A novel peptide (GX1) homing to gastric cancer vasculature inhibits angiogenesis and cooperates with TNF alpha in anti-tumor therapy. BMC Cell Biol. 2009;10:63.

33. Wu X, Yan Q, Huang Y, et al. Isolation of a novel basic FGF-binding peptide with potent antiangiogenetic activity. J Cell Mol Med. 2010; 14(1-2):351-356.

34. Laakkonen P, Porkka K, Hoffman JA, Ruoslahti E. A tumor-homing peptide with a targeting specificity related to lymphatic vessels. Nat Med. 2002;8(7):751-755.

35. Lesniak WG, Kariapper MS, Nair BM, et al. Synthesis and characterization of PAMAM dendrimer-based multifunctional nanodevices for targeting alphavbeta3 integrins. Bioconjug Chem. 2007;18(4): $1148-1154$.

36. Thannhauser TW, Konishi Y, Scheraga HA. Analysis for disulfide bonds in peptides and proteins. Methods Enzymol. 1987;143:115-119.

37. Lee G, Ge B. Cancer cell expressions of immunoglobulin heavy chains with unique carbohydrate-associated biomarker. Cancer Biomark. 2009;5(4):177-188.

38. Pakkala M, Hekim C, Soininen P, et al. Activity and stability of human kallikrein-2-specific linear and cyclic peptide inhibitors. JPept Sci. 2007; 13(5):348-353.

39. Malik N, Wiwattanapatapee R, Klopsch R, et al. Dendrimers: Relationship between structure and biocompatibility in vitro, and preliminary studies on the biodistribution of ${ }^{125}$ I-labelled polyamidoamine dendrimers in vivo. J Control Release. 2000;65(1-2):133-148.

40. Singh P, Gupta U, Asthana A, Jain NK. Folate and folate-PEG-PAMAM dendrimers: Synthesis, characterization, and targeted anticancer drug delivery potential in tumor bearing mice. Bioconjug Chem. 2008;19(11): 2239-2252.

41. Toshinari T, Eiji Y, Chie K, Atsushi H, Kenji K. Synthesis of a polyamidoamine dendron-bearing lipid having sugar moieties and its use for preparation of nonviral gene vectors. Res Chem Intermed. 2009;35(8-9): 1005-1014.

42. Duan Y, Yang C, Zhang Z, Liu J, Zheng J, Kong D. Poly(ethylene glycol)-grafted polyethylenamine modified with G250 monoclonal antibody for tumor gene therapy. Hum Gene Ther. 2010;21(2): 191-208.

43. Shukla R, Thomas TP, Peters J, Kotlyar A, Myc A, Baker JR Jr. Tumor angiogenic vasculature targeting with PAMAM dendrimer-RGD conjugates. Chem Commun (Camb). 2005;14(46):5739-5741.

44. Sarin H, Kanevsky AS, Wu H, et al. Effective transvascular delivery of nanoparticles across the blood-brain tumor barrier into malignant glioma cells. J Transl Med. 2008;6:80.

45. Prieto MJ, Schilrreff P, Tesoriero MV, Morilla MJ, Romero EL. Brain and muscle of Wistar rats are the main targets of intravenous dendrimeric sulfadiazine. Int J Pharm. 2008;360(1-2):204-212. 


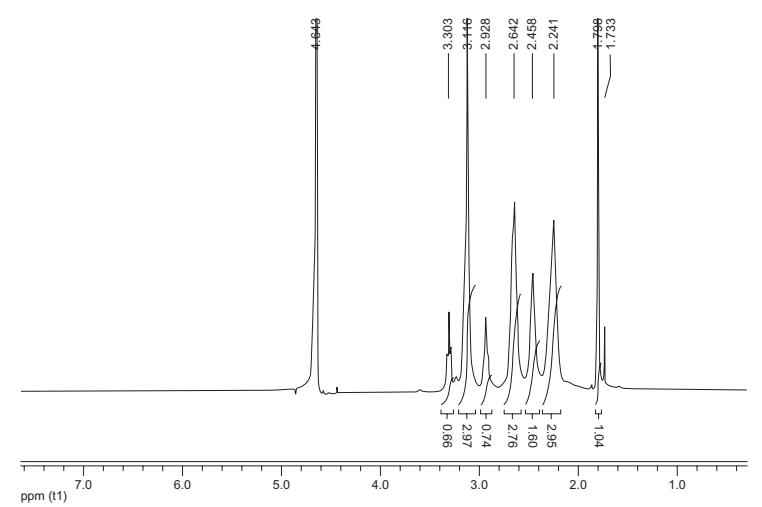

Figure SI ' $\mathrm{H}$ nuclear magnetic resonance spectrum $\left(300 \mathrm{mHz}, \mathrm{D}_{2} \mathrm{O}\right)$ of the acetylated polyamidoamine.

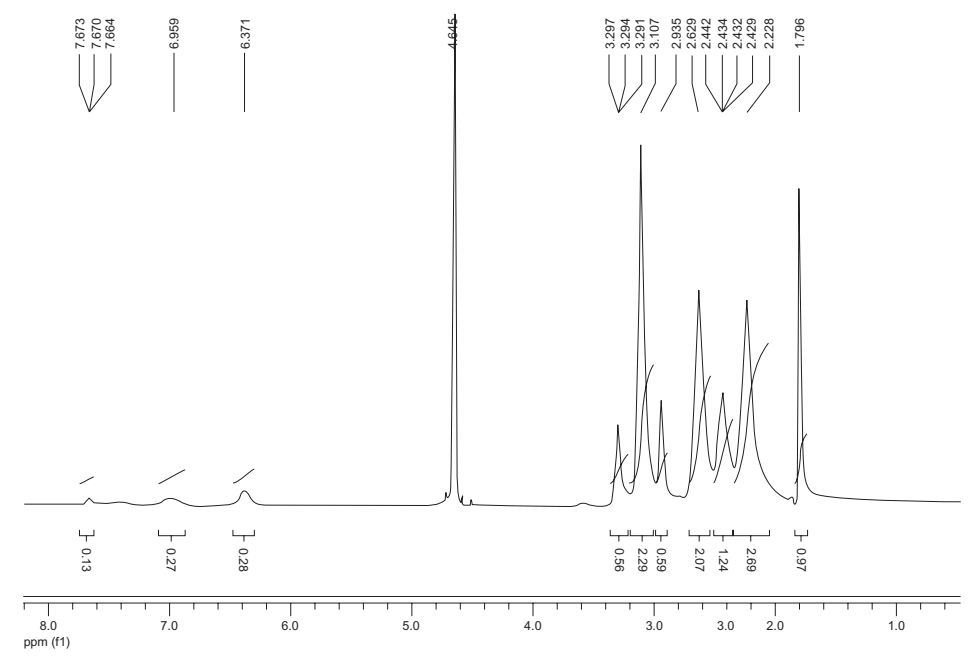

Figure S2 ' $\mathrm{H}$ nuclear magnetic resonance spectrum $\left(300 \mathrm{mHz}, \mathrm{D}_{2} \mathrm{O}\right)$ of the fluorescence-labeled acetylated polyamidoamine.

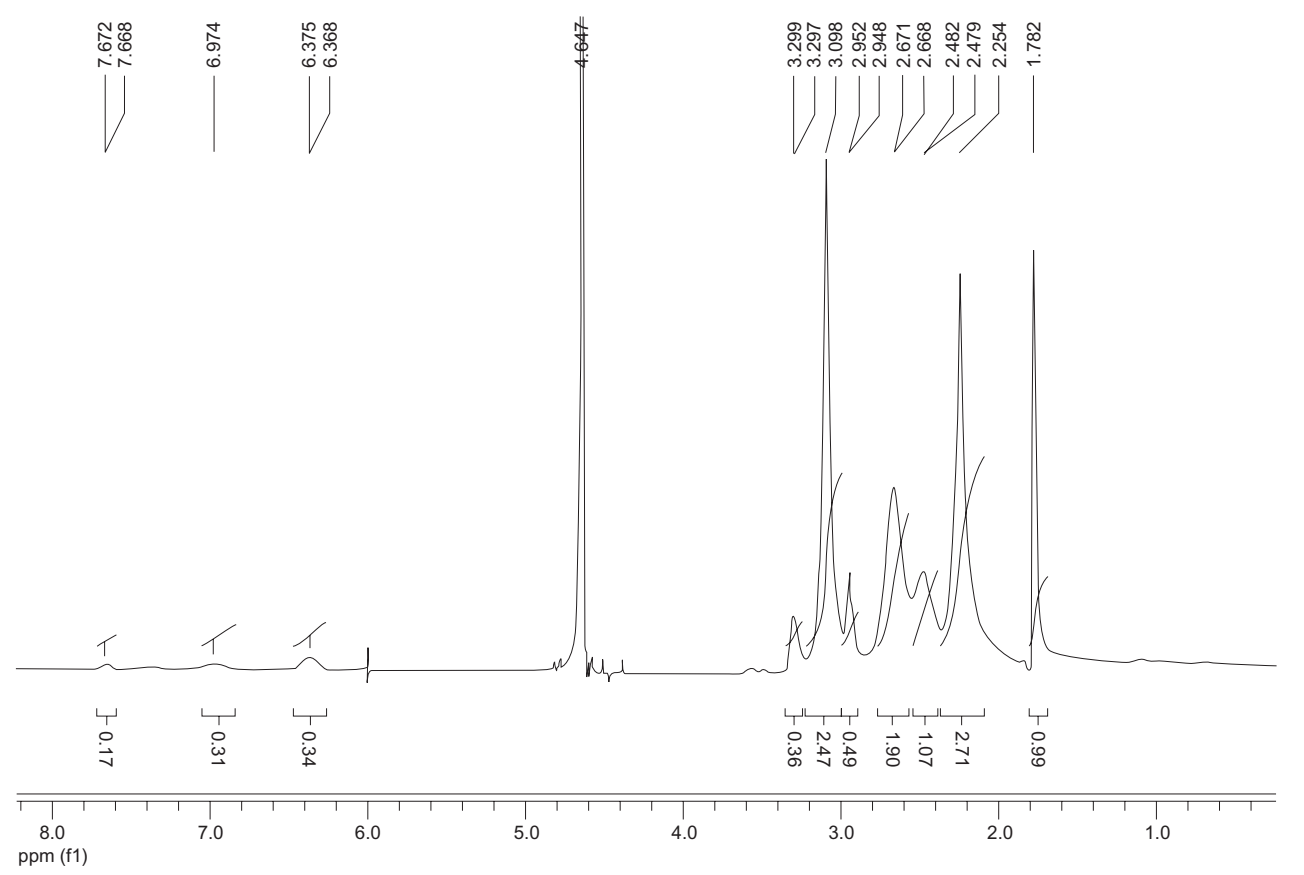

Figure S3 'H nuclear magnetic resonance spectrum $\left(300 \mathrm{mHz}, \mathrm{D}_{2} \mathrm{O}\right)$ of the fluorescence-labeled acetylated polyamidoamine lung cancer targeting peptide. 

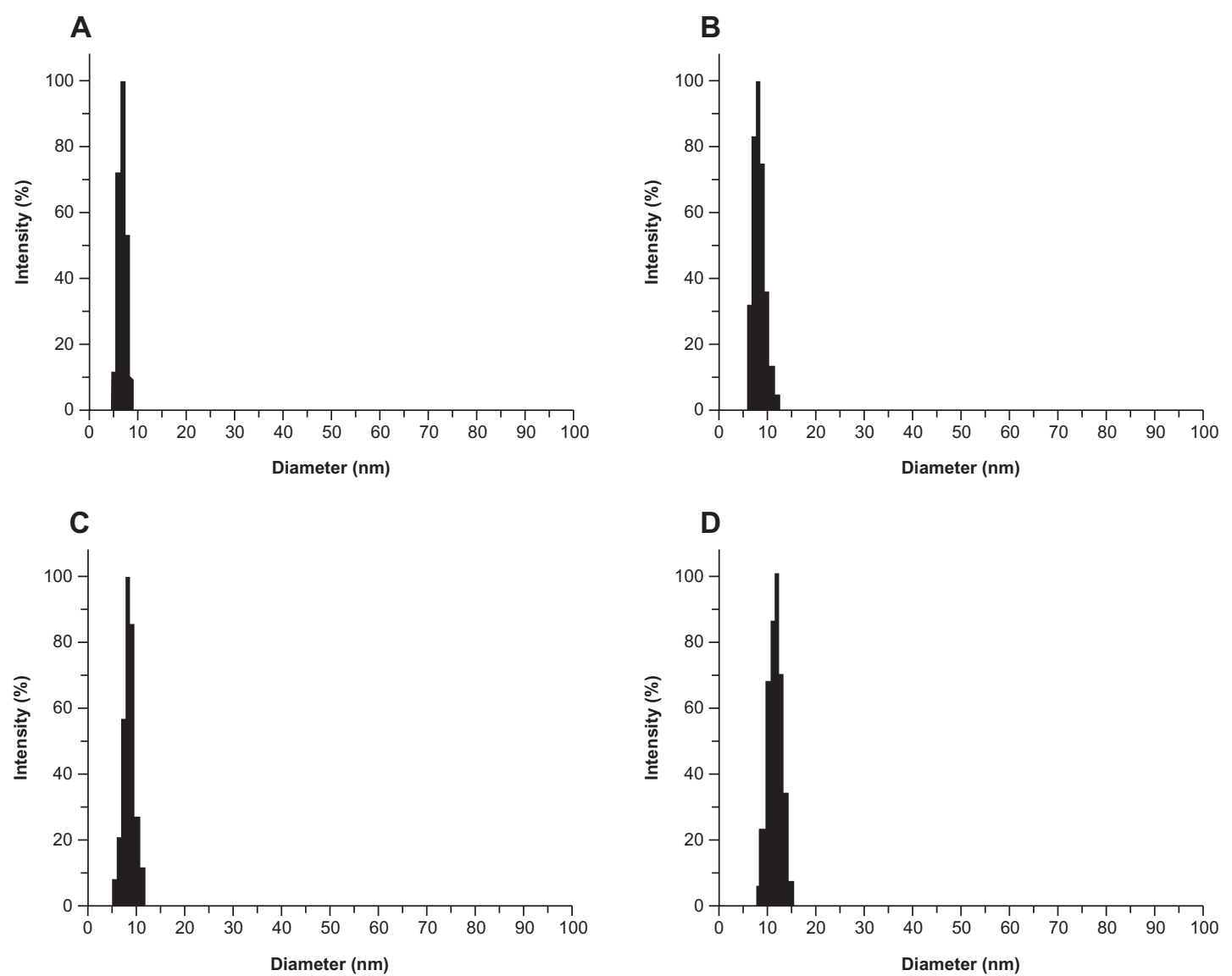

Figure S4 Laser light-scattering assay results. The polyamidoamine particle size was about $7 \mathrm{~nm}(\mathbf{A})$ and the particle size of acetylated polyamidoamine (B) fluorescencelabeled acetylated polyamidoamine (C), and fluorescence-labeled acetylated polyamidoamine lung cancer targeting peptide (D) becomes bigger and bigger.

\section{Publish your work in this journal}

The International Journal of Nanomedicine is an international, peerreviewed journal focusing on the application of nanotechnology in diagnostics, therapeutics, and drug delivery systems throughout the biomedical field. This journal is indexed on PubMed Central, MedLine, CAS, SciSearch ${ }^{\circledR}$, Current Contents ${ }^{\circledR} /$ Clinical Medicine,
Journal Citation Reports/Science Edition, EMBase, Scopus and the Elsevier Bibliographic databases. The manuscript management system is completely online and includes a very quick and fair peer-review system, which is all easy to use. Visit http://www.dovepress.com/ testimonials.php to read real quotes from published authors. 